\title{
The Development And Status Of Extracorporeal Shock Wave Lithotripsy
}

\author{
Zhaoqian $\mathrm{Xu}^{1, \mathrm{a}}$, Yin $\mathrm{Xu}^{2, \mathrm{~b}}$ \\ ${ }^{1}$ Chemstry and Environment Metrology Department, Zhejiang Province Institute of Metrology, 222 \\ Tianmu Mountain Road, China 310013 \\ ${ }^{2}$ China Jiliang University, 258 Xueyuan Road, China 310018 \\ a jujube2265@163.com, bu_yin@outlook.com
}

Keywords: Lithotripsy; Lithotripter; ESWL; Shock wave generator

\begin{abstract}
Urinary calculi shall afflict people for decades. People invented many devices for treatment of calculi. Extracorporeal shock wave lithotripsy because of its relative safety, less trauma, low cost, good treatment effect, has soon become a preferred method in the treatment of urinary calculi. With the development of ESWL, variety and quality of lithotripter are improved. But some problems still exit.
\end{abstract}

\section{History of Lithotripsy}

Urinary calculi are one of the most common urological diseases. Not only that, it is a very old disease, and shall afflict people for decades. As a result, many thousands of years ago people had been willing to risk their lives for treatment to relieve the pain. In the absence of anesthesia, through perineum incision surgery is not only a terrible process for patients, also can leave sequela and associated with high mortality ${ }^{[1]}$. Patients required recovery time for three months or more, many of whom have erectile dysfunction, incontinence and other sequelae, and some patients even died of sepsis.

Through a cannula dilating the urethra, Egyptians had smaller calculi taken out successful. Some forms of lithotripsy using a catheter can be traced back to the 9th century during Byzantine period ${ }^{[2]}$. In the 18th century, with the development of chemical technology, people have tried to dissolve calculi by chemical means, but all failed. People began to consider again with a more direct treatment of urinary calculi. The 18th century, Haller suggested that if a stone was too big to extract, it could be drilled. The lithotrites was based on Haller's view as the first basic principle.

In 1824, Percy reported to the Academy of Sciences in Paris about a monk of Citreaux who crushed his bladder calculi by himself. The monks moved a metal catheter into the bladder, and then steel rod with an end cut into chisel through the catheter was moved into his bladder. A hammer hit the other end of the steel rod and calculi were cut into small pieces. The calculi finally were excreted in the urine. The monks took about a year to discharge all gravel. He is the first person who have destroyed calculi mechanically ${ }^{[3,4]}$. In the early 19 th century, Gruithusisen designed a lithotripter. The calculi were located at the end of the hollow straight tube, and put a drill bit into the tube to destroy stones $^{[5]}$. Civiale invented a instrument called trilabe. The trilabe was made up of two tubes. The external tube was mounted on the hinged arm to grab calculi and the inner tubes with a drill bit or other grinding tools to destroy the calculi ${ }^{[6-8]}$. In 1824 Civiale used his improved lithotripter to destroy calculi in a living subject successfully. Although Gruithusisen's and Civiale's instruments promoted the development of lithotripsy, and for the patients lithotripsy have higher security than 
invasive surgery, surgeons believed invasive surgery is more reliable than "blind" lithotripsy. So the invasive surgery was still preferred in the early 19th century.

In the 1870s, Bigelow of Boston invented a new type of surgery. In the procedure, a rubber ball was used to suck out calculi fragments from another large diameter catheter. The surgery made it possible that all fragments can be removed in one time. In 1877, Max Nitze invented the first cystoscope, and in 1886 an improvement was made to it. It was the first time that the urologist had the vision of the surgery in patients' bladder ${ }^{[9]}$. In 1908, Young of Baltimore invented the first lithotriptoscope ${ }^{[10]}$. The invention and integration of cystoscope and lithotriptoscope promoted the development of modern lithotrites.

With the development of technology, many kinds of new type of lithotrites were designed to be invented. Goodfiend designed ultrasonic probe in 1973. As the probe can't bend and is not easy to heat dissipation, it is limited in application ${ }^{[11]}$. In 1976, Mauermayer and Hartung designed a punch lithotrite, which can keep conditions of the good visibility ${ }^{[12]}$. The pneumatic lithotrite was successfully developed in lausanne, Switzerland, 1990. The device uses compressed air to activate a solid probe in a manner similar to that of a jackhammer ${ }^{[13]}$. At present, electrohydraulic and laser shock wave lithotrite is also used in the treatment of calculi. Now the safety and the success rate of lithotrite has been greatly improved.

\section{History of ESWL}

Extracorporeal shock wave lithotripsy technology because of the advantage of its relative safety, less trauma, low cost, good treatment effect, has now become a preferred method in the treatment of urinary calculi.

In 1955, the Soviet engineer Yutkin found the electrohydraulic effect, and began to research on the use of electrohydraulic effect for the treatment of calculi ${ }^{[14,15]}$. After a decade of research, Yutkin eventually developed the first electrohydraulic source lithotripter. The relevant research on extracorporeal shock wave lithotripsy was originated in Germany by the aerospace firm Dornier. In the early 1960s, the federal republic of Germany Dornier aerospace engineers found that when the supersonic aircraft was in flight, the gas shock waves caused metal fatigue. In 1966, when an engineer of Dornier touched the shock wave steel target, the contact area was not hurt but had the feeling of electric shock. The engineers realized that this is the effect of shock wave to human tissue. In 1969, with the support of the Ministry of National Defense of the federal republic of Germany, Dornier began to research on the relationship between shock wave and animal tissue, and set out to research and development of extracorporeal shock wave lithotripter. In 1974, Dornier developed the first shock wave lithotripter testing machine. There was almost no difference between principle of the testing machine and widely used electrohydraulic lithotripter at present. The preliminary experimental results showed that the shock wave can effectively destroy calculi, and the results had high repeatability. Since there was no design of positioning device, the success rate was low. As a result, in 1978, Dornier designed a new testing machine with two ultrasonic probe positioning device. In 1979, after a series of research and improvement, Dornier successfully developed the world's first prototype medical extracorporeal shock wave lithotripter, and named it human machine 1(HM1). A year later in 1980, the HM1 lithotripter successfully cured one patient with kidney calculi at the urology department at the University of Munich. In 1982, Dornier developed HM2 lithotripter which was simpler in operation than HM1. In 1983, after the optimization for the modification of the HM2 
lithotripter, the first commercial HM3 lithotripter was developed by Dornier. HM3 lithotripter was soon approved by the United States Food and Drug Administration (FDA) just after its publishing. Therefore extracorporeal shock wave lithotripsy was widely approved throughout the world. Many countries had also started the development and production of extracorporeal shock wave lithotripter. The success of HM3 lithotripter inspired the study of shock wave lithotripter. Then, in addition to electrohydraulic lithotripter, electromagnetic, piezoelectric lithotripter had been successfully developed in succession. Although with the development of science and technology, the variety of lithotripters positioning devices and the coupling devices also had a very large development, but Dornier HM3 lithotripsy was still the "gold standard" for the efficacy of shock wave lithotripter ${ }^{[16,17]}$.

With the upgrading of lithotripter manufacturing technology, lithotripter also has developed to the fourth generation. The first generation of lithotripters mainly refers to the electrohydraulic lithotripter represented by Dornier HM3 lithotripter. And the first generation of the lithotripters mainly adopted hydraulic electric shock wave source and the treatment table with a basin. The second generation of lithotripters is developed in 1986, which mostly eliminated the basin and adopted the water sac as the dry therapy to couple the shock wave and the human body. The dry therapy also narrowed the focal area of the second focus and minimized the damage of surrounding tissues, and it could complete the process of surgery without anesthesia. The third generation of lithotripters was introduced in the 1990s. In addition to the treatment of urinary calculi, it can also finish some minor urology surgeries. The fourth generation of shock wave lithotripter has a good safety profile and patients can receive minimal analgesia ${ }^{[18,19]}$.

China began experiments in extracorporeal shock wave lithotripsy in the late 1970s. In early 1983, extracorporeal shock wave lithotripter was started developing. A year later, in 1984, the prototype E8410 was successfully developed, which used the same electrohydraulic source as the HM3. After experiments of efficacy and safety, the prototype successfully destroyed a $13 \mathrm{~mm}$ x $10 \mathrm{~mm}$ kidney calculus in the clinical trials in 1985, which proved the its reliability. On the basis of E8410 lithotripter, a variety of electrohydraulic lithotripters were developed. Extracorporeal shock wave lithotripter had the characteristics of the efficacy, safety and painless, which had been widely recognized. Therefore, the shock wave lithotripsy also gradually became the first choice for the treatment of urinary calculi. It also promoted the commercial development of the lithotripter. In the late 1980s, a rapid development of lithotripter manufacturer occurred in China. But because of the excessive pursuit of profit, good and bad are intermingled in the quality of lithotripter. Problems appeared such as the short of shock waves focal length, low resolution of positioning system and poor quality of components.

In 1985, the Taipei Veterans General Hospital in Taiwan used HM3 lithotripter in the clinical treatment for the first time. Only in the first year, it completed treatment of 1800 cases of patients with kidney calculi, which is the maximum number in the Asian region at that time. The same year, Hong Kong Sao Paulo Hospital started using HM3 lithotripter in the clinical treatment. In the next few years, China also imported several shock wave lithotripters from France and Germany. But because of its high price and maintenance fee, imports of lithotripter gradually declined. With the improvement of domestic production technology level, the domestic price of lithotripter was obviously higher than that of imported lithotripter. China has become the world's largest producer of lithotripter, and the number of lithotripter manufacturers is more than the sum of all other countries in the world ${ }^{[6]}$. 


\section{Classification of Extracorporeal Shock Wave Lithotripter}

Extracorporeal shock wave lithotripter is mainly composed of the shock wave generator, the positioning system, the control system, the coupling device and the treatment bed. The shock wave generator and the positioning system are the core components of a lithotripter, and lithotripters are usually classified according to the different kinds of shock wave generators and positioning systems.

In addition to the electrohydraulic energy source, piezoelectric crystals, electromagnetic membranes, focused lasers and even micro-explosions can be used to generate shock waves. At present, the shock wave generator of commercialized lithotripters mainly use electrohydraulic, electromagnetic and piezoelectric energy source.

The role of positioning system of extracorporeal shock wave lithotripter is to ensure that calculi are accurately in the focus area, and observe the processes and outcomes of the operation. There are three positioning systems, the x-ray positioning system, the type-b ultrasonic positioning system and the $\mathrm{x}$-ray/ type-b ultrasonic positioning system.

\section{The Electrohydraulic Lithotripter}

The electrohydraulic lithotripters use electrohydraulic effect to generate shock waves. Under the water, the tip of the electrode generates instantaneous high-pressure discharge to produce shock waves, which are strong pulse discharge of nanosecond level. Shock waves reflect by a half ellipsoidal reflector, and then enter the body through the coupling medium and the energy focus on the second focus point (figure 1). Calculi will be destroyed by stress effect, cavitation effect and squeezing effect produced by shock waves.

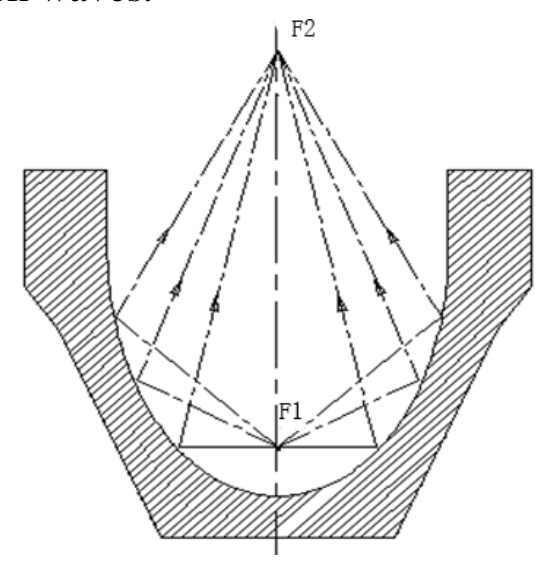

Fig.1 the principles of electrohydraulic lithotripter

The electrohydraulic pulse waveform is stable, and has short rise time. At the second focus point, the focused shock wave peak will be up to $100 \mathrm{MPa}$, and the pulse width can reach $0.3 \sim 1$ by setting proper parameters. The electrohydraulic energy is stronger. Its adjustable range is relatively bigger and clinical treatment effect is better. However, discharge of electrohydraulic energy source is not stable and the focus point is also easily drifted.

\section{The Piezoelectric Lithotripter}

Piezoelectric generators have a hemisphere installed on many piezoelectric crystals (figure 2). When the high voltage with high frequency passes through piezoelectric crystals, piezoelectric crystals have inverse piezoelectric effect. Piezoelectric crystals produce stretching vibration, and the water 
molecules vibrate, which generate shock waves. All these shock waves focus on focus point of the hemisphere where the calculi are positioning, and calculi will be destroyed.

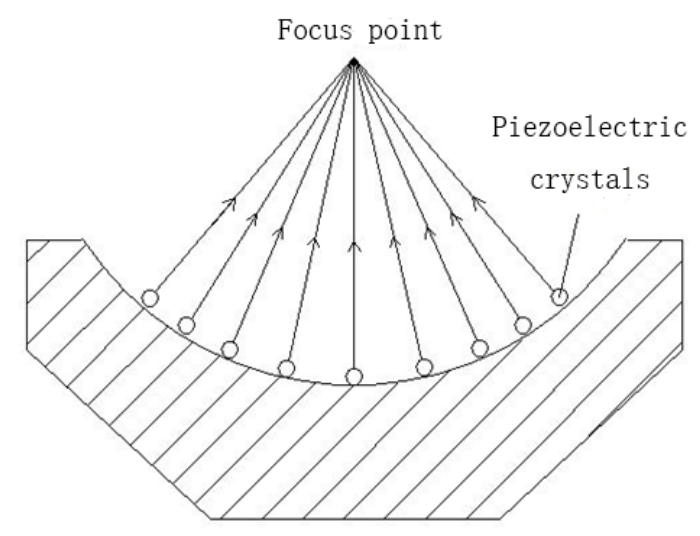

Fig. 2 the principles of piezoelectric lithotripter

The piezoelectric energy source has a single frequency, less noise and less damage to the surrounding tissue. But penetration ability is weak, and the attenuation is serious, leading to a lower efficiency of treatment. Furthermore, the structure of the piezoelectric is complex and it has high technical requirements, which makes the less application of piezoelectric lithotripters than electrohydraulic and electromagnetic lithotripters.

\section{The Electromagnetic Lithotripter}

The electromagnetic lithotripter is designed according to the law of electromagnetic induction. When the pulse electric current with high frequency and high voltage passes through the coil, coil creates a magnetic field. The plate metal film near the front end of the coil will be vibrated under the action of induced magnetic field, and the vibration promotes the water molecules to generate shock waves. Shock waves pass through the lens and focus on the other side. The calculi positioned on the focus point can be destroyed by focused shock waves.

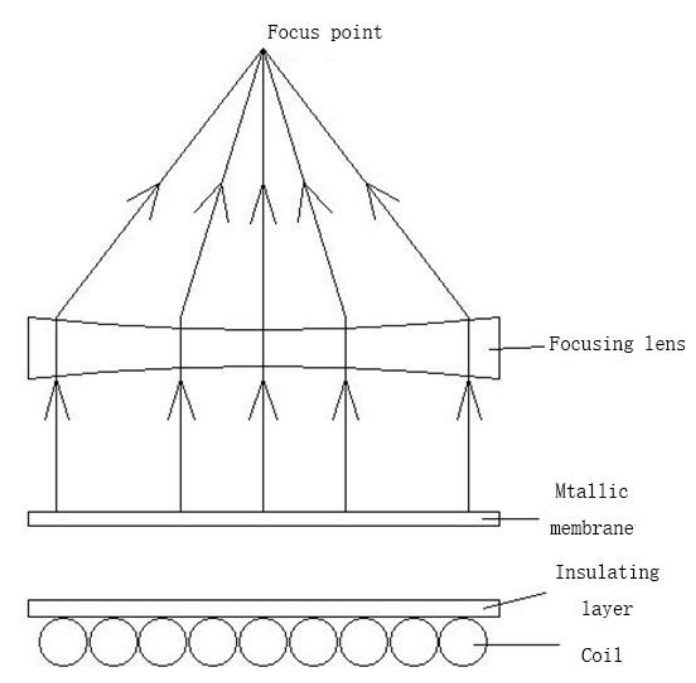

Fig. 3 the principles of electromagnetic lithotripter

\section{The Positioning System}

X-ray positioning systems, depending on the mechanical structure, can be divided into two-beam 
$\mathrm{x}$-ray positioning and rotating c-arm positioning. The two-beam x-ray positioning system consists of two sets of the x-ray device. Both set of x-ray unit is installed at an angle to each other on the lithotripter. When the calculi are located in focus point by the both two systems, it can be confirmed the calculi is in the focus point. Rotating c-arm positioning system is equipped with a set of x-ray device in two segments. X-ray projection center is set to pass through the focus point. In initial position, adjust calculus to the focus point. With the c-arm's rotation of an angle, move the calculi to the focus position, so it ensures that the calculi are located on the focus point.

Type-B ultrasonic positioning system is based on the principle that the spread of ultrasound in different acoustic impedance media will reflect back different signals. The ultrasonic probe is usually installed with the shock wave generator. According to the installation position of the probe, the probe can be divided into the internal probe and the external probe. Make sure the extension of the center of a ultrasonic probe passes through the focus point, the calculi can will be located by using of range finder function of the type-B ultrasonic.

$\mathrm{X}$-ray positioning system operation is easy to master quickly, and the image is clear. The process of operation can be directly observed. However, X-ray radiation will do damage to human body, and the device is costly. Type-B ultrasonic positioning system doesn't have radioactivity and almost cause no harm to human body. Type-B ultrasonic positioning system applies great to tissues which are unfavorable to expose to X-ray, and it displays clear for both positive and negative calculi. It can also achieve real-time continuous tracking and surveillance. Compared with the X-ray positioning system, type-B ultrasonic positioning system has advantages of low cost and easy to operate.

The $\mathrm{x}$-ray/ type-b ultrasonic positioning system is both installed on the $\mathrm{X}$-ray and type-B ultrasonic device. The combined system gives full play to their respective advantages. However, this system is expensive, and the requirement of operation is also higher.

\section{The Present Problems of the Extracorporeal Shock Wave Lithotripter}

The main problem of extracorporeal shock wave lithotripters at present is that the theory of shock wave lithotripsy technology is imperfect. The relationship between the parameters and the efficacy of shock waves is not very clear yet. Acoustic field characterization in the focus area lacks of perfect theory. Actual acoustic field inside patients and the theoretical error also remain to be proven.

Lithotripter productions in China have a certain gap in the manufacturing process compared with advanced foreign lithotripters. Although clinical treatment effect are similar, but the clinical efficiency is lower than the advanced lithotripter. At present the parameters of the shock waves lack of related standards, and there is no verification device, verification regulations and mandatory scrapping regulations. It causes lack of long-term supervision and management of lithotripters and even some early lithotripter are still in use. There are serious safety hazard.

\section{References}

[1] Shelley HS. Cutting for the stone[J]. Journal of the history of medicine and allied sciences. 1958;13(1):50-67.

[2] Marketos SG, Lascaratos J, Malakates S. The first record of lithotripsy, in the early Byzantine era[J]. British journal of urology. 1994;74(4):405-8.

[3] Herr HW. 'Crushing the stone': a brief history of lithotripsy, the first minimally invasive 
surgery[J]. BJU international. 2008;102(4):432-5.

[4] MURPHY LJ. SELF-PERFORMED OPERATIONS FOR STONE IN THE BLADDER[J]. British journal of urology. 1969;41(5):515-29.

[5] Zajaczkowski T, Zamann AM, Rathert P. Franz von Paula Gruithuisen (1774-1852): lithotrity pioneer and astronomer. On the 150th anniversary of his death $[\mathrm{J}]$. World journal of urology. 2003;20(6):367-73.

[6] Riches E. The history of lithotomy and lithotrity[J]. Annals of the Royal College of Surgeons of England. 1968;43(4):185.

[7] Kiefer JH. Jean Civiale (1792-1867)[J]. Investigative urology. 1968;6(1):114-7.

[8] Poisson M. Statistical research on conditions caused by calculi by Doctor Civiale[J]. International Journal of Epidemiology. 2001;30(6):1246-9.

[9] Bigelow HJ. Litholapaxy, or, rapid lithotrity with evacuation: A. Williams; 1878.

[10] Young H, Davis D. Practice of Urology, vol[J]. Philadelphia: WB Saunders Company. 1926:147.

[11] Goodfriend R. Disintegration of ureteral calculi by ultrasound[J]. Urology. 1973;1(3):260-3.

[12]Mauermayer W, Hartung R. Der Stein-Punch, ein neues Prinzip zur Sicht-Lithotripsie[J]. Urologe A. 1976;15:164.

[13]Denstedt J, Eberwein P, Singh R. The Swiss Lithoclast: a new device for intracorporeal lithotripsy[J]. The Journal of urology. 1992;148(3 Pt 2):1088-90.

[14] Yutkin L. Electrohydraulic effect[J]. ASTIA Translation. 1955.

[15] Yutkin L. Electrohydraulic Effect and Its Industrial Application[J]. Mashinostroenie, Leningrad. 1986.

[16]Lingeman JE. Extracorporeal shock wave lithotripsy. Development, instrumentation, and current status[J]. The Urologic clinics of North America. 1997;24(1):185-211.

[17]Grocela JA, Dretler SP. Intracorporeal lithotripsy. Instrumentation and development[J]. The Urologic clinics of North America. 1997;24(1):13-23.

[18]Nomikos MS, Sowter SJ, Tolley DA. Outcomes using a fourth - generation lithotripter: a new benchmark for comparison?[J]. BJU international. 2007;100(6):1356-60.

[19]Lingeman JE. Is the Sonolith Vision fourth-generation lithotripter effective for the treatment of renal calculi?[J]. Nature Clinical Practice Urology. 2008;5(6):300-1. 